\title{
EL DERECHO INTERNACIONAL PÚBLICO Y EL DERECHO INTERNACIONAL PRIVADO
}

\author{
OYARCE-YuZZELLI, Aarón*
}

SUMARIO: 1. Introducción. - 2. El derecho internacional público. - 3. El derecho internacional privado. - 4.Nuevas tendencias en el derecho internacional. -5 . Conclusiones.

\section{Introducción}

Debido a la globalización existente en el mundo los derechos supranacionales cobran mayor relevancia en la actualidad, especialmente dos derechos internacionales, el derecho internacional público y el internacional privado. Estudiaremos las características básicas de estos derechos, desde su origen histórico su adecuación a la legislación nacional, las instituciones básicas, así como las nuevas tendencias del derecho internacional.

\section{El derecho internacional público}

El derecho internacional público ${ }^{309}$ estudia las relaciones entre los sujetos del derecho internacional público, en sus orígenes los Estados y luego se crean estos sujetos debido al avance del derecho ${ }^{310}$.

* Ricercatore del Consiglio Nazionale delle Ricerche d'Italia (CNR), en el Instituto di Studi Giuridici Internacionali (ISGI) (Roma - 2008), Scientiae Juridicae Doctor (c) por la Wake Forest University Schoool of Law; International Legal Researcher de la Wake Forest University School of Law, Winston Salem NC-USA (2007), Doctor en Derecho (SJD), Lima-Perú, Master en Diritto Privato Europeo de la Università degli Studi di Roma "La Sapienza", Master en Derecho Americano (LL.M.) de la Wake Forest University School of Law, Winston Salem-USA, Corso di alta formazione in Diritto Romano de la Università di Roma "La Sapienza", Abogado de la Universidad San Martín de Porres, Lima-Perú. Profesor de pre y post grado en derecho romano, comparado e internacional en la USMP, UNFV, URP, UNP, UPT, Director del Instituto de Investigación de la Facultad de Derecho y Ciencia Política de la URP. E-mail: aoyarcey@ hotmail.com

309 Sobre el Derecho Internacional Público ver: CASSESE, Antonio, Diritto Internazionale, Il Mulino, Bologna 2003. Costa RudA, Podestá, Derecho Internacional Público, Tea, Buenos Aires 1985; Donde el autor señala que el Derecho internacional público es el conjunto de normas jurídicas que rigen las relaciones de los Estados entre sí y también la de éstos con ciertas entidades que, sin ser Estados, poseen personalidad jurídica internacional. Además, el derecho internacional comprende las normas jurídicas que rigen el funcionamiento de las organizaciones internacionales y sus relaciones entre sí. Ver también: PlanAS SuAREZ, Simón, Derecho Internacional Público, Hijos de Reus, Vol., I, Madrid 1916, pp. 1-51

${ }^{310}$ El derecho internacional público es la rama del derecho que se encarga de las relaciones entre sujetos de derecho internacional público, entre ellos podemos mencionar: a) los Estados, los cuales desde su origen fueron los sujetos fundamentales del DIP, pero gracias al desarrollo del derecho internacional, surgieron nuevos sujetos, producto de la integración interestatal o creación de personas jurídica nuevas; b) organizaciones internacionales, producto de las necesidades internacionales, y que los estados no podían hacer frente, entre ellas podemos señalar: las Naciones Unidas, la OEA, etc.; c) empresas multinacionales, muy criticadas como sujetos del DIP pero debido a su importancia económica y laboral son consideradas como sujetos; $d$ ) organizaciones no gubernamentales internacionales; e) alzados en armas, quienes por pelear la guerra siguiendo las normas del derecho de guerra, adquieren este status internacional, no teniendo este reconocimiento los terroristas; f) la iglesia, no únicamente la católica, sino toda denominación inscrita en las Naciones Unidas; 


\subsection{Origen}

El origen del derecho internacional público sería el ius gentium, aplicable a todos los extranjeros en Roma y común inclusive a los animales, y también el ius fetiale ${ }^{311}$, quienes se

g) los estados no autónomos, un ejemplo clásico es el caso de Puerto Rico; $h$ ) los individuos como entes receptores de normas del derecho internacional. Cabe mencionar además, que el derecho internacional no sólo regula las relaciones de paz, regidas por el Convenio de Viena de 1980 sobre derecho de los Tratados, curso que regularmente es enseñado en Perú, sino también el derecho de guerra, todo el procedimiento de declaración formal, combate, límites, treguas, fin etc., como se hace en las facultades europeas.

${ }^{311}$ Los feciales eran sacerdotes; y como todo elius sacrum, también el ius fetiale estaba constituido por formulas, por ritos, por solemnidades, de ceremonias que el pueblo Romano, regidos por rígidos preceptos religiosos sostenedores, que debían de observar para declarar la guerra o para establecer la paz. Y como en las Doce tablas no estaba escrito el derecho pontificio o el derecho augural, pero ambos estaban consagrados en libros secretos, así podemos afirmar con seguridad que todas las fórmulas y ritos que constituían el derecho fecial, estaban recogidas en libros religiosos especiales (libros y comentarios), confiados al cuidado del colegio de los feciales, el cual probablemente tenía el encargo de llevar nota de todos los tratados que Roma contraía con otros Estados FUSINATO, Op. cit., p. 34; Extraño ver que los feciales no vienen mencionados por OLGIVE, Ancient Culture and Society, The Romans and Their Gods, Chatto \& Windus, London 1969. Eran nombrados de por vida por ((cooptatio)). La Cooptatio es la elección de una persona para un cargo en una institución hecha por el predecesor, y elegidos entre las mejores familias patricias y luego de la ley Ogulnia también se le dio oportunidad a los plebeyos de acceder a éste cargo. MoMMSEN, Rom. Forschungen, I, p. 115. Lo contrario es sostenido por Weiss en Daremberg-Saglio, 2,2, ((Fetiales)), insistiendo en el carácter típicamente patricio de ésta magistratura. FERRARI, Op. cit., V., p. 255. Los feciales, como los otros sacerdotes romanos, eran honorados y poseían santidad e inviolabilidad, también fuera del territorio patrio, FUSINATO, Op. cit., p. 37 : Sacrum etiam inter exteras gentes legatorum ius. TACITO, Ann., III, 80.

Los feciales estaban presididos por un pater patratus (En esta institución de los feciales se haría referencia de pater patratus como líder de una institución, como el pater familias en la familia romana, cómo el pontífice máximo en el colegio de pontífices o la virgo vestales máxima entre las vestales), de carácter duradero y perpetuo, como el del pontifex maximus en el colegio de los pontífices, como el magister de los Salii (Los Salii eran sacerdotes romanos antiguos, divididos en dos colegios: uno del Palatino y el otro del Quirinale. El sodalicio de los Salii fue instituido por Numa para honorar y custodiar un escudo caído milagrosamente del cielo, como signo de la futura potencia militar de Roma. Sus miembros eran elegidos de entre los patricios, y eran consagrados a Marte y a Quirino, que celebraban con danzas guerreras. El 1 de marzo los Salii paseaban en procesión al escudo (ancilia), chocándo las lanzas y cantando un antiguo Carmen saliare. La fiesta terminaba el 19 de marzo, primer día de las Quinquatrie. En octubre se celebraban ceremonias similares hasta el armilustrio, 19 de octubre, cuando las armas sagradas eran repuestas) y de los Hermanos Arvales (Los Hermanos Arvales eran doce miembros de colegio sacerdotal romano, instituido según la leyenda por Rómulo, quienes celebraban en mayo de cada año, sacrificios y ceremonias de purificación de las divinidades agrestes. Se dedicaban además al culto de la diosa Día, una divinidad arcaica romana, luego se identificaron con Cerere, que protegía la tierra. The Arval Brethren were a body of priest in ancient Rome who offered annual sacrifices to lares and gods to guarantee good harvest. The term can be translated as Brothers of the fields), como el de la virgo vestalis maxima entre las vestales, ver: FUSINATO, Op. cit., p. 39. Él era el encargado de la consagración del foedus y de la declaración de guerra, también le eran reservadas atribuciones especiales, entre las cuales la representación del pueblo romano (Aquí podemos apreciar que los feciales utilizaban sus funciones diplomáticas, como lo hacen los funcionarios de cancillería en la actualidad.). Respecto a su etimología algunos la explican como el pater familias representaba a sus hijos, así el pater patratus al pueblo de Roma: patratus estaría a indicar la consagración de ésta paternidad artificial, BAVIERA, Op. cit., p. 13, citando a Lange, 13, 265. Otros señalan que patrare proviene de sancir, que indica la misión de los feciales de consagrar o de un nuntium, en relación a la misión asignada, Livius, 38.3.8.

Las funciones principales eran: $a$ ) ser jueces y mensajeros de los acuerdos (foedera) de paz y de guerra; b) ser publici legati y nuntii (Los nuncios actualmente son los representantes de la Santa Sede en el extranjero, son diplomáticos que poseen inmunidades que el derecho internacional les concede. Son los embajadores de la guerra y de la paz de los romanos, quienes poseen legitimidad divina en sus decisiones), (representantes del populus romanus), en las relaciones externas de Roma con otros pueblos; $c$ ) tomar determinaciones en relación a la guerra; $d$ ) levar a cabo el rito de celebración del acuerdo (foedus), la rerum repetitio (pedido de reparación que precedía la declaración de guerra) y declarar el bellum iustum piumque (declaración de guerra). Ver: MÉndez Chang, El Ius Fetiale como Derecho Supranacional Vigente para Roma y los demás Pueblos, Seminario de Derecho Romano XXVI Aniversario, Universidad de Veracruz, México 2000, p. 13. Los tratados 
encargaban de las relaciones internacionales públicas romanas, tanto las relaciones de paz, como las relaciones de guerra; celebrando tratados internacionales, que creaban alianzas o iniciaban conflictos internacionales. Además el origen del derecho internacional público en el derecho romano se le otorga al ius gentium, el cual utilizaban los extranjeros y quienes estaban excluidos de utilizar el ius civilis, el cual era exclusivo y excluyente para los romanos.

\subsection{Principios}

Actualmente los principios del derecho internacional público son los siguientes: a) la igualdad soberana de los Estados (en 1945 la Carta de las Naciones Unidas ha incluido en el art. 2.1 este principio; $b$ ) no intervención en los asuntos internos y externos entre los estados. Ser prohíbe a los Estados de realizar actividades específicas o el constreñir a un Estado extranjero a realizar determinado comportamiento. Por ejemplo la no intervención de las naciones extranjeras en las guerras civiles; $c$ ) prohibición de la amenaza y del uso de la fuerza. Art 2.4. de la Carta de las Naciones Unidas. Desde 1945 la paz se ha convertido en el fin supremo de la comunidad internacional. Por ello existe la necesidad de evitar el desarrollo de conflictos armados, capaces de provocar el peligro de la humanidad; $d$ ) solución pacífica de las controversias. Art. 2.3 de la Carta de las Naciones Unidas obliga a las naciones a resolver sus controversias de manera pacífica, para prevenir cualquier amenaza a la paz, a la seguridad y a la justicia; e) respeto de los derechos humanos. La adopción de la Carta de las Naciones Unidas y, la Declaración Universal de los Derechos Humanos, se establece que ningún Estado puede negar que los derechos humanos deben de ser respetados en el mundo; f) la autodeterminación de los pueblos. Propuesto por la revolución francesa, todos los pueblos y las naciones pueden definir sus instituciones y políticas nacionales; $g$ ) soberanía, comprende los siguientes poderes y derechos: el poder de imperio sobre todos los individuos que viven sobre el territorio del Estado; el poder de utilizar y disponer libremente del territorio sujeto a la jurisdicción del Estado, cumpliendo todas las actividades consideradas necesaria o útiles o para la población; el derecho a excluir a los Estados del ejercicio de la soberanía en el territorio; el derecho de pretender la inmunidad para sus propios órganos que han actuado como oficiales; el derecho a exigir a los otros Estados la inmunidad de jurisdicción sobre los actos cumplidos como ente soberano ${ }^{312}$.

\section{El derecho internacional privado}

El derecho internacional privado ${ }^{313}$ es el derecho que regula las relaciones entre personas naturales o jurídicas de derecho privado, pero donde existe un elemento extranjero

de paz podrían asimilarse actualmente como los tratados de comercio, tratados de integración. Los cuales otorgan libertades como principios básicos. Véase el caso de la Unión Europea que posee como principales principios: $a$ ) libertad de circulación, de bienes, servicios, capitales, personas; $b$ ) libertad de establecimiento; $c$ ) igualdad; $d$ ) no discriminación. Sería este el origen del derecho de integración, comercio internacional, el federalismo, etc. Como en el derecho romano, en el derecho actual también se presentan problemas similares con los derechos de los extranjeros en los territorios nacionales. Realizando el estado una clasificación de los extranjeros: $a$ ) naturalizados.

312 : CASSESE, Antonio, Diritto internazionale, Il Mulino, Bologna 2003, pp. 61-84.

313 Sobre el concepto del Derecho Internacional Privado ver: OYARCE-YUZZELLI, Aarón, Derecho Internacional Privado, UIGV, Lima 2005, pp. 21-26. El derecho internacional privado es aquel derecho que se encarga de regular las relaciones jurídicas entre personas de derecho privado, donde exista un elemento extranjero. El Derecho internacional privado también es llamado derecho conflictual, porque al existir elemento extranjero no se sabrá qué ley aplicar, la ley del nacional o la ley del extranjero. Además no se sabrá quién será el juez competente. El autor nos señala que el objeto del Derecho Internacional Privado es señalar el juez 
presente, sin importar la relevancia de éste. Por el simple hecho de existir un elemento extranjero, será de aplicación el derecho internacional privado, porque crea un conflicto de aplicación de normas.

El derecho internacional privado, por su nomenclatura se presta a errores, pues no únicamente estudia temas de derecho privado, sino todos los temas con conflicto normativo, sean estos de derecho público o privado.

\subsection{Origen}

Existen dos teorías en cuanto a su origen, la unitaria y la teoría de la autonomía.

a) unitaria, la cual señala que el derecho internacional privado nace dentro del derecho internacional público y recién alcanza su independencia con la escuela histórica del derecho, donde Savigny lo convierte en una cátedra independiente del derecho internacional público en la universidad en 1850 ;

b) autonomía, la cual indica que el derecho internacional público nace en Roma con dos instituciones; el pretor peregrino, quien se encargaba de resolver las relaciones jurídicas cuando existía en ellas un elemento extranjero, sea la relación jurídica misma o los sujetos extranjeros; y la institución de los recuperatores ${ }^{314}$.

El derecho internacional privado llega al Perú gracias al Tratado de Montevideo de 1892 y luego gracias al Código de Bustamante, que plasma los resultados de la conferencia realizada en la Habana Cuba en 1928. Este código fue incluido dentro del Código Civil de 1984 en el Libro X, pero solamente los artículos con contenido civil; provocando esto un gran problema en cuanto a su estructura. Además debemos mencionar que no ha sido actualizado desde 1928, ni para la promulgación del código civil de Fernández Sessarego.

competente y la ley aplicable, siguiendo la teoría bipartita o anglosajona, distinta a la tripartita o latina que agrega la nacionalidad y el trato al extranjero. Ver también RAPALINI, Liliana, Temática de Derecho Internacional Privado, Lex, La Plata 2002, pp. 14-15. Además MosCONI, F. Diritto Internazionale Privato e Processuale, 2da. Ed., Utet, Torino 2001, pp. 7-9. El cual nos habla sobre los risvolti pratici delle problematiche internacional privatistiche del forum shopping, que es el fenómeno de la búsqueda del tribunal potencialmente más favorable, es decir el juez ante quién es conveniente iniciar el proceso. KELLER DE Orchansky, Berta, Nuevo Manual de Derecho Internacional Privado, Plus Ultra, Buenos Aires 1990, p. 15; Quién nos señala además de la existencia del elemento extranjero que necesariamente debe existir en una relación jurídica de derecho internacional privado, sino se aplicará el derecho nacional regular. El derecho internacional privado permite a la persona elegir la legislación más favorable a nivel mundial y poderse acoger a ella si no vulnera a terceros civil ni penalmente. Debemos señalar que existe un gran problema en cuanto a la denominación del derecho internacional privado. El término privado implica para algunos juristas, el tratamiento únicamente de materias de derecho civil y derecho comercial, excluyendo a las otras, como el derecho penal, o procesal, etc. Más aun si esta materia se encuentra codificada dentro del código civil. Es por ello que el derecho internacional privado se adapta mejor al término: derecho conflictual. Se aplicará el derecho conflictual (conflicts of laws), siempre que exista conflicto en cuanto a la aplicación de la norma nacional o extranjera.

${ }^{314}$ Sobre la institución de los recuperatores ver: Novíssimo Digesto Italiano, pp. 1076-1081. Erano giudici, i quali pronunciavano riuniti in collegio e costituivano, accanto al iudex unus e ll'arbiter, uno degli organi iudicanti. L'origine dei recuperatores é probabilmente da vedere in procedimenti di tipo internazionale istituiti per il recupero dei beni, che si assumevano occupati o sottratti da comunitá o da singoli individui stranieri. Il termine recuperator sembra appunto derivare dall'originaria funzione di questi giudici, che servivano a recuperare beni caduti in mano enemica o straniera. 


\subsection{Principios}

\section{Dentro de sus principales principios encontramos:}

a) la extraterritorialidad de la norma, que nos indica que la norma nacional se aplica en territorio extranjero y que la norma extranjera es de aplicación en territorio nacional, deshaciendo la teoría de la territorialidad de la norma, implica no solo la aplicación de derecho supranacional en territorio nacional, sino normas de países extranjeros, cuando el derecho internacional privado lo señale ${ }^{315}$.

Los principios correspondientes son: i) principio real o protección de intereses, donde se aplica la ley nacional a toda conducta que afecte los intereses o bienes jurídicos del propio Estado o de sus ciudadanos sin considerar la nacionalidad del agente; ii) principio de personalidad o de nacionalidad, la ley peruana se aplica a ciudadanos nacionales en el lugar donde se encuentren.

b) trato al extranjero, principio que equipara las condiciones entre el nacional y el extranjero, estableciendo un principio actual, el principio de igualdad, el extranjero debe regirse por la misma regulación que los nacionales, no puede ser discriminado por razón de nacionalidad o etnia. Inicialmente el extranjero era considerado como peregrino u hostis, un enemigo para los romanos, esto es a consecuencia de la teoría de la hostilidad natural y posterior nacimiento del estado bajo el contrato social, donde el gobernante debió de crear un enemigo foráneo, para poder unificar a la población y redirigir la violencia fuera del estado romano. Por ello actualmente se desvanece la teoría de la hostilidad natural y del trato al extranjero como enemigo ${ }^{316}$.

315 Sobre la extraterritorialidad de la norma en el derecho penal peruano ver: VILLAVICENCIO TERREROS, Felipe, Derecho penal parte general, Grijley, Lima 2006, pp. 188-192. "La aplicación de la ley penal puede darse a hechos delictivos ejecutados fuera del territorio nacional (derecho penal internacional)".

${ }^{316}$ Sobre el trato al extranjero en el derecho romano ver: OYARCE YUZZELLI, Aarón, El status civitatis, en Derecho Romano, Instituciones, En progreso: La nacionalidad fue un derecho máximo en Roma, como lo es actualmente, aquellos que eran cives poseían derechos que no poseían los extranjeros. En el status civitatis las personas podían ser o cives romanos o peregrino u hostis, los enemigos de Roma, cada uno de ellos con derechos diversos y muy diferenciados. En la utilización de la normatividad romana, el ius civiles, era utilizado de manera exclusiva y excluyente por los cives, dejando de lado al peregrino, quien utilizaba el ius gentum. Según este status el cives contaba con todos sus derechos pero respetando los otros status como el familiae o el social. Nacionalidad o ciudadanía poseen dos conceptos, uno anglosajón que señala que la nacionalidad es un contrato entre un Estado y un individuo, generando derechos (a la seguridad interna e internacional, seguridad social, trabajo, educación, vida digna, sufragio, etc.) y obligaciones (sufragio, servir a la patria, tributar). Esta teoría del contrato es derivada de la teoría del contrato social sobre la creación del Estado, ver: Rousseau, Kant, Locke, Hobbes, Mommsen. El segundo concepto es romanista, donde se señala que la nacionalidad es un vínculo de la persona con factores en común, como con el pueblo, la tradición, religión, costumbres, etc. La nacionalidad genera entre el ciudadano y la nación derechos y obligaciones de obligatorio cumplimiento, tanto para el Estado, como para el ciudadano. Ejemplo de los deberes del ciudadano podemos indicar los siguientes: a) servir a la patria; b) sufragar; c) tributar. Así también el ciudadano por su condición tendrá derecho a exigir todos los derechos enunciados en la constitución y en las normas inferiores, como: $a$ ) educación; $b$ ) salud; $c$ ) seguridad social; $d$ ) vivienda, etc. Sobre el status civitatis ver: ARANGIO RUIZ, Vincenzo, Instituciones de derecho romano, De Palma, Buenos Aires 1973, pp. 59-65. Los cives son ciudadanos de pleno derecho, derechos que podían acceder gracias a la celebración de foderas. Ver también: MoMmsen, Teodoro, Compendio del derecho público romano, Buenos Aires 1942, pp. 37-43. Las causas que dan ingreso en la ciudadanía son las siguientes: a) el nacimiento dentro del matrimonio legítimo, según las reglas vigentes así para el patriciado, como también en lo esencial para la dependencia; $b$ ) el nacimiento fuera del matrimonio legítimo, según las normas de la dependencia; $c$ ) la adopción como hijo de un hijo de familia de derecho latino; $d$ ) la traslación de un latino a Roma bajo la égida de su derecho nacional; $e$ ) la liberación de un latino a Roma bajo la égida de su derecho nacional; $f$ ) la liberación, no solamente de la esclavitud, sino también de la situación de aquellos 
c) la reciprocidad; que se aplica a falta de tratado entre las parte y consiste en la obligación de dos naciones por la existencia de un precedente vinculante;

d) reciprocidad futura, es la creación del precedente que servirá como elemento vinculante para ambas naciones. Es un principio político y dependerá de la Nación que creará el precedente. Claro ejemplo de reciprocidad futura en Perú era el caso Fujimori Perú-Japón, donde no existía tratado ni extradición anterior que sirviera de precedente, únicamente existió una expulsión de una ciudadana japonesa del ejército rojo, pero las expulsiones no son consideradas precedente.

\subsection{Excepciones a la aplicación de la norma extranjera}

En cuanto a las excepciones a la aplicación de la norma extranjera en territorio nacional, podemos mencionar las siguientes:

a) violación al orden público, orden público entendido como el conjunto de principios y normas fundamentales de la nación, en derecho internacional público es llamado cláusula de reserva, donde, si una cláusula de un tratado vulnera la normatividad nacional, esta quedará sin entrar en vigencia hasta que las partes lo acuerden ${ }^{317}$.

b) violación a las buenas costumbres, en el caso chileno también se menciona la moral. En el Perú tenemos un gran problema, porque las costumbres son distintas de localidad en localidad, e inclusive poseemos diversas comunidades nativas y campesinas con costumbres permitidas en algunas y prohibidas en otras ${ }^{318}$.

c) retorsión: que es la prohibición expresa de la aplicación de la norma extranjera en territorio nacional o del reconocimiento de sentencias y laudos arbitrales extranjeros. el caso de los países socialistas que prohíben el uso de norma imperialista;

hombres libres que se hallaban en lugar de esclavos; $g$ ) la concesión del derecho de ciudadano en la forma antigua de recepción de una familia en el gremio de los patricios. La nacionalidad se pierde, a parte del caso de muerte, o por entrar en la esclavitud el individuo que hasta ahora disfrutaba de tal derecho, o por entrar en esclavitud el individuo que hasta ahora disfrutaba de tal derecho, o por la agregación jurídicamente válida a otro Estado con el cual Roma tuviere celebrado un convenio, y esto, por la ley de incompatibilidad de varias nacionalidades. GuZMÁN Brito, Alejandro, Derecho Privado Romano, T.I, Editorial Jurídica de Chile, Santiago 1993, 327-333. Los ciudadanos miembros plenos del populus Romanus y participan íntegramente del derecho romano público y privado (civil pretorio y extraordinario). Por lo que al primero respecta, tienen derecho a votar en las asambleas ciudadanas (suffragium), de ser elegidos para las magistraturas y los sacerdocios (honores 9 y de servir en el ejército.

${ }^{317}$ El principal ejemplo de violación al orden público es la adhesión a la convención del mar, lo cual significa para el Perú la reducción de 188 millas marítimas de nuestro mar territorial, por ello, me parece extraña la adhesión del Perú a la convención del mar para poder resolver el conflicto de delimitación marítima con Chile. Entre otros ejemplos podemos mencionar la homologación de un matrimonio homosexual celebrado en el extranjero, ello no será posible en el Perú por afectar al orden público, o principio o norma fundamental del estado peruano. Otro ejemplo es el caso de derecho de sucesiones, donde se pretende dividir los bienes según las legislaciones foráneas, estas hacen distinción entre los hijos, sean estos matrimoniales o extramatrimoniales o en el caso de los árabes, los hijos matrimoniales pero dependiendo de cuál esposa en tiempo, poseerá mayor derecho sobre la herencia.

${ }^{318}$ El ejemplo actual de violación a las buenas costumbres es el caso Badani, quien fue expulsado de Chile por haber atentado contra las buenas costumbres al haber contraído nupcias bajo el rito religioso musulmán con tres mujeres. Caso más actual aun, es el caso de las colombianas A1, quienes están siendo expulsadas del país por atentar contra las buenas costumbres. 
d) falta de adecuación, el no poseer los procedimientos ni instituciones para implementar o cumplir sentencia extranjera, esta ya no es una excepción en el DIP, el Estado está obligado a implementar y aplicar la normatividad internacional ${ }^{319}$.

e) la no reciprocidad, el Perú no reconocerá sentencia extranjera, si el país extranjero no reconoce nuestras sentencias. La no reciprocidad significaría además la existencia de un precedente negativo en cuanto al reconocimiento de sentencias peruanas en el extranjero o aplicación de normatividad peruana.

\subsection{Categorías jurídicas}

Estudiaremos las principales categorías del derecho internacional privado, como el elemento extranjero, el fraude a la ley, el reenvío, entre otras.

\subsubsection{El elemento extranjero}

Una categoría jurídica pertenece al derecho internacional privado, si posee dentro de sí un elemento extranjero. Si la relación jurídica no posee elemento extranjero, la legislación aplicable será la nacional, si posee, la legislación aplicable será la de derecho internacional privado. Un claro ejemplo es el matrimonio de peruana con peruano celebrado en Perú, va ha ser regulado por el derecho peruano, código civil. Envés el matrimonio de peruano con extranjera, celebrado en Perú será de competencia exclusiva del derecho internacional privado por el elemento extranjero, la esposa. El elemento extranjero puede ser:

a) el sujeto, fácil de reconocer, mediante su documento de identidad, pasaporte o carnet de extranjería;

b) el objeto, por ejemplo en el caso del comercio internacional, los bienes en la transacción son el elemento extranjero;

c) la relación jurídica; algunas categorías jurídicas son de derecho internacional, sin importar los sujetos o el objeto, es el caso por ejemplo de los delitos internacionales, los cuales serán de derecho internacional porque así lo designaron los tratados. También debemos de señalar que algunas relaciones jurídicas son de derecho nacional, pero se convierten en relaciones de derecho internacional. Por ejemplo: el matrimonio entre peruanos, que es nacional, se convierte en relación de derecho internacional si algunos de los cónyuges establece su domicilio en el extranjero, o si ambos cónyuges variasen su domicilio.

\subsubsection{El fraude a la ley}

Una institución básica del DIP es el fraude a la ley, fraudem legis, que es la búsqueda de la ley más favorable a nivel internacional. En términos técnicos, es la variación real del elemento de conexión para favorecerse de una ley más benigna, siempre y cuando no vulnere civil ni penalmente a terceros. Ejemplos de fraude a la ley en el derecho actual son los casos de matrimonios homosexuales en los países donde sus países lo permiten en su normatividad; el divorcio en países más breves en cuanto a sus procedimientos. Un ejemplo de la señalación de la ley aplicable utilizando el elemento de conexión voluntad es el Convenio 80/934/CEE

319 . El caso más reciente en el Perú es el Caso Bagua, donde el gobierno peruano obvió aplicar el derecho de consulta que poseen las comunidades nativas y campesinas por reconocimiento internacional, ejemplo la Convención 169 de la OIT, por no poseer la reglamentación para aplicarla 
sobre la ley aplicable a las obligaciones contractuales, del 19 de junio de 1980. El Convenio se aplica a las obligaciones contractuales en situación que impliquen un conflicto de leyes, incluso si la ley designada es la de un Estado no contratante, excepto en los casos: $a$ ) cuestiones relativas al estado civil o capacidad de las personas físicas; $b$ ) obligaciones contractuales relativas a los testamentos, los regímenes matrimoniales y otras relaciones familiares; $c$ ) obligaciones derivadas de instrumentos negociables; $d$ ) convenios de arbitraje y de elección de foro; $e$ ) cuestiones pertenecientes al derecho de sociedades, asociaciones y personas jurídicas, etc. Como ejemplo actual en el fraude a la ley podemos mencionar el caso de los futbolistas y artistas italianos, quienes para evadir el sistema de imposición fiscal italiano, establecieron sus residencias en Luxemburgo, donde el sistema impositivo es menor. La Corte dei conti inició procedimiento de cobranza coactiva, con posible inicio de juicio penal por haber realizado conductas para no tributar. Finalmente los inculpados tuvieron que llegar a una transacción con el fisco italiano, dado que no era un fraude a la ley del derecho internacional privado, porque la variación del elemento de conexión fue simulado, y además esta variación no debe causar daños a terceros civil ni penalmente. Es también el caso de Claudio Pizarro y el fisco alemán y peruano.

\subsubsection{El reenvío}

Otra institución básica del DIP es el reenvío, que es el segundo envío realizado por la legislación enviada, debido a las diferencias de las normas de derecho internacional privado que poseen los países en el mundo. El reenvío puede ser de primer, segundo, tercer grado, y reenvío circular. El caso más reciente sobre el reenvío en el Perú es el de los agentes de seguridad contratados por los Estados Unidos para prestar servicios en Iraq y Afganistán. El contrato señalaba que la ley aplicable sería la ley de Virginia (USA) basándose en el elemento de conexión voluntad de las partes, pero la ley de Virginia señalaba que todos los contratos celebrados en el extranjero se rigen por la ley del lugar de ejecución, (Afganistán). La ley afgana nos señalaba que los contratos celebrados en extranjero se rigen por el lugar de celebración. Provocando ello que la norma aplicable sea la peruana, aquella que cuestionaba el desempeño de las actividades de los agentes de seguridad.

\subsubsection{La calificación de la categoría jurídica}

Otra figura del derecho internacional privado es la calificación de la categoría jurídica. La calificación hace referencia a la calificación de la categoría jurídica. Denota qué legislación va a calificar la categoría jurídica, será la legislación del lugar de celebración del acto jurídico, del accidente, del lugar de comisión del delito, e irá con calificación previa a la legislación enviada, o será la legislación enviada la que calificará la categoría jurídica. Por ello aparecen dos teorías:

a) lex fori, que señala que quien calificará la categoría jurídica es la ley del lugar de origen del acto jurídico, y por ende llegará calificada;

b) lex causa, esta teoría no señala que quien calificará la categoría jurídica es la ley del envió, por lo tanto la categoría jurídica llegará sin calificación previa. Un ejemplo de esta discusión doctrinaria sobre el tipo de calificación, lo vemos en los casos de responsabilidad extracontractual, donde los Estados Unidos busca que las categorías jurídicas vengan calificadas desde el país de origen (lex fori) de este modo la reparación civil sería mucho menor, casos de class action, temas de seguros, derecho aeronáutico, etc. Casos emblemáticos en Perú son: el caso Yanacocha y el camión de mercurio. Donde se discutía la 
aplicación de la lex fori o lex causa, si se aplicaría el concepto de reparación civil peruano o los torts de USA. Y los casos Faucett y Aeroperú.

\subsection{Clases de normas}

Existen dos clases de normas, las directas y las indirectas.

a) las directas, son regularmente los tratados relativos a instituciones específicas, como la compra venta internacional, adopción internacional, etc. Estos tratados contendrán la ley aplicable, el juez competente, obligaciones y derechos, etc.;

b) las normas Indirectas: son aquellas, remisivas, remitentes o conflictuales, aquellas que señalan la ley aplicable; a esta ley nos debemos de remitir para encontrar la ley aplicable. En el caso peruano, las normas conflictuales se encuentran en el título III del Libro X del Código Civil, Ley Aplicable. Se componen de categoría jurídica y elementos de conexión: ley del domicilio, ley de la voluntad, lex rei sitae, lex delicti commissi, etc.

\subsection{Competencia}

En cuanto a la señalación del juez competente, este se lo designa gracias a la competencia exclusiva de los jueces nacionales que cada país designa. En el caso peruano es de competencia exclusiva del juez nacional: $a$ ) estado y capacidad de la persona; $b$ ) bienes inmuebles situados en el Perú, salvo que se trate de sucesión internacional; $c$ ) quiebra de empresas; $d$ ) prórroga de la competencia, cuando las partes se someten al juez nacional; $e$ ) cuando se trate de obligaciones que se cumplan en Perú.

\subsection{Aplicación}

Para la aplicación del derecho internacional privado, se debe de seguir el siguiente procedimiento:

a) verificar si en la relación jurídica existe un elemento extranjero;

b) recurrir a un tratado bilateral o multinacional que regule la relación jurídica;

c) si no existe tratado vigente se debe recurrir al libro $\mathrm{X}$ del Código Civil Peruano, a la par al Código de Bustamante, porque la promulgación del Libro X no deroga al Código de Bustamante, más bien toma parte de su articulado; si no existe solución jurídica, recurrir a;

d) los principios doctrinales del derecho internacional privado. 


\section{Nuevas tendencias en el derecho de internacional}

Actualmente el derecho internacional cobra mayor relevancia a nivel mundial debido a los procesos de integración a nivel continental ${ }^{320}$, como es el caso de la Unión Europea, el

${ }^{320}$ Derecho regional entendido como derecho de integración: ver: TESAURO, Giuseppe, Diritto Comunitario, Cedam, Padova 2003; refiriéndonos a la Unión Europea, como modelo de integración para la CAN, Mercosur y otros. Ver también: AlPA, Guido e CAPILli, Giovanna, Lezioni di Diritto Privato Europeo, Cedam, Padova 2007. El derecho de integración es la ciencia que estudia los procesos asociativos entre dos o más Estados, ya sea que la vinculación se limite a la formación de zonas de libre comercio, unión económica o la integración total. Es un conjunto de normas, conductas y valores que rigen los procesos de integración, involucrando en ellos a las instituciones que hacen posible su desarrollo, es decir la ciencia que estudia los procesos asociativos entre dos o más estados, ya sea que la vinculación se limite a la formación de zonas de libre comercio, unión económica o la integración total. Responde a la voluntad soberana de los gobernantes y redunda no sólo en lo económico sino también en lo político, lo jurídico, lo cultural y a él le sucede el derecho comunitario, esto es el sostén jurídico llamado a regir las relaciones comunitarias en sus diversas especies, el debido respeto al extranjero ha de ser el elemento ideológico que permita la concreción y consecución del bloque. El tratado o acuerdo macro es aquel que da origen al bloque de integración y constituye, sin duda, la carta constitucional básica. Su virtualidad radicará en el encuadre de dicho tratado dentro de los principios contenidos en las constituciones de cada Estado miembro. Los principios en el derecho de integración son progresivos según avance el sistema de integración, siendo estos: a) libertad de circulación de bienes, servicios, capitales y personas; $b$ ) libertad de establecimiento; $c$ ) igualdad; $d$ ) no discriminación. Estos principios no operan en su totalidad, serán progresivos, de acuerdo al grado de integración existente. Por ejemplo: en el Nafta solamente operan los principios de libertad de circulación de bienes, servicios y capitales, no opera la libre circulación de personas. En el caso del Can sí opera la libertad de circulación de personas, pero en calidad de turistas, los cuales pueden permanecer sin visa un máximo de 90 días. En el caso de la Unión Europea sí operan todos los principios, para los ciudadanos de los países miembros.

Las formas de integración son las siguientes: a) zona de libre tránsito o de libre comercio; regularmente entre países colindantes, con la finalidad de promover el tráfico comercial, para lo cual las transacciones comerciales no son gravadas y los productos ingresan al país bajo el procedimientos de las franquicias tributarias; Tratados de Libre comercio, que tendrían la misma finalidad de las zonas de libre tránsito y libre comercio, eliminándose el arancel. Se trata entonces de un proceso jurídico comercial transitorio por el cual los Estados parte regulan sus intercambios comerciales concediéndose exenciones progresivas aduaneras, de gravámenes y restricciones; $b$ ) unión tarifaria, donde dos o más países acuerdan el intercambio de productos con arancel ceo entre ellos y con arancel externo común respecto al intercambio con otros países; $c$ ) arancel común, se aplica el arancel externo común para las importaciones desde países terceros; $d$ ) mercado común, son intercambios que se realizan libremente entre los países miembros de un sistema de integración, se retiran todas las restricciones a la inmigración e inversión entre fronteras; e) comunidad económica, se da como ejemplo el Tratado de Roma del 25 de marzo de 1957, donde se promueve un desarrollo armonioso de las actividades económicas, en el conjunto de la comunidad, y una expansión continua y equilibrada, estabilidad creciente, y elevación del nivel de vida; $f$ ) unión monetaria; $g$ ) unión total, es el caso de la Unión Europea, donde operan todos los principios enunciados en una unión. Donde los países miembros han transferido a la UE sus competencias legislativas en determinados asuntos, como la agricultura y la pesca. Además existen competencias que se comparten entre la UE y las administraciones nacionales. Todas las constituciones nacionales deben de adecuarse al tratado de Lisboa, no pueden existir contradicciones a la norma supranacional. Ver también: Tesauro, Giuseppe, Diritto Comunitario, 2da ed. Cedam, Padova 2001, p. 3 ss. La Unión Europea moderna tiene como inicio el discurso de Churchill en la Universidad de Zurich en septiembre de 1946 “...Noi dobbiamo costruire gli Stati Uniti d'Europa... Il primo passo nella ricostruzione della famiglia europea deve essere una partnership tra Francia e Germania”. El Tratado CECA (European Coal and Steel Community) de París el 18 de abril de 1951, firmado por Francia, Alemania, Italia los tres países del Benelux (Bélgica, Holanda y Luxemburgo), luego el CED (Comunidad Europea para la Defensa) de 1952 que no entró en vigencia, dopo il EURATOM del 25 de marzo de 1957. En 1957 se firma en Roma el Tratado que establece la European Economic Community EEC, de 1957, llamado también el Tratado de Roma El Tratado de Maastricht firmado el 7 de febrero entrado en vigor el 1 de noviembre de 1993, con este documento los miembros ven un modelo federal. Tratado de Ámsterdam, del 2 de octubre de 1997, entrada en vigor el 1 de mayo de 1999. El 1 de enero de 2002 entra en vigencia el Euro. El 1 de mayo ocho países de la Europa central y oriental (Estonia, Letonia, Lituania, Polonia, República Checa, Eslovaquia y Hungría) entran a la Unión (conformada por Austria, Bélgica, Dinamarca, Finlandia, Francia, Alemania, Grecia, Irlanda, Italia, Luxemburgo, Holanda, Portugal, UK, España y Suecia). El 1 de enero del 2007 Bulgaria y Rumania entra a la Unión, actualmente son 27 países 
Mercosur, la Comunidad Andina y futuros proyectos como el Alca. Esto provoca la aparición de principios como: $a$ ) libertad de circulación, de bienes, capitales, servicios y de personas; $b$ ) la libertad de establecimiento; $c$ ) la igualdad; $d$ ) la no discriminación. Además provoca, con el derecho local, conflictos de jerarquía, derecho nacional vs derecho supranacional, que para nosotros posee solución, por ser el derecho supranacional de mucha mayor jerarquía que el derecho nacional.

\section{Conclusiones}

Tanto el derecho internacional público como el derecho internacional privado son derechos supranacionales que poseen gran relevancia en la actualidad, dada la globalizacón del derecho y los sistemas de integración que generan nuevas categorías jurídicas supranacionales y nuevas jerarquías que modifican las jerarquías tradicionales.

Para conocer los derechos supranacionales debemos de regresar al derecho romano y su aplicación, tanto a nacionales como a extranjeros, además reconocer la gran influencia del derecho natural sobre estos.

miembros. Y permanecen como candidatos: Croacia, Macedonia y Turquía. En diciembre del 2007 se firma el Tratado de Lisboa que modifica el texto de los tratados precedentes. Ver también: Moussis, Nicholas, Access to European Union, Euroconfidentiel, Genial 1997. ZANGHI, Claudio, Istituzioni di Diritto dell'Unione Europea, Giappichelli, Torino 1995. Ver también: TRIGgIANI, Ennio, L'Unione Europea secondo la riforma di Lisbona, Levante Editori, Bari 2008. Actualmente el derecho de integración y su modelo máximo, el de la Unión Europea, enfrenta una gran crisis, por la crisis económica de Grecia, que pone en tela de juicio la expansión de la unión. Ampliar el ingreso a Turquía significará un gran reto porque será el primer país islámico en integrar la Unión, pero debemos mencionar que Turquía es muy importante visto que es Roma II. Actualmente, algunos economistas e internacionalistas señalan que esta unión ha creado patologías, las económicas actuales debido a la crisis económica griega, la discriminación contra los países más pobres como Rumanía y sus etnias de Roms y Sintis, etnia errantes de gitanos. El origen del derecho de integración también es romano y no actual como mencionan algunos integracionistas y economistas. Como veremos a lo largo del desarrollo del libro y en especial en el capítulo dedicado a los feciales, Roma establecía alianzas con las naciones extranjeras, para entablar relaciones económicas y de defensa, para ello celebraban foedus, de donde proviene la palabra federado. Siendo los feciales el origen del derecho de integración. 